NASA/CR—2006-214454

\title{
Heat Transfer and Fluid Dynamics Measurements in the Expansion Space of a Stirling Cycle Engine
}

Nan Jiang and Terrence W. Simon

University of Minnesota, Minneapolis, Minnesota 


\section{NASA STI Program . . . in Profile}

Since its founding, NASA has been dedicated to the advancement of aeronautics and space science. The NASA Scientific and Technical Information (STI) program plays a key part in helping NASA maintain this important role.

The NASA STI Program operates under the auspices of the Agency Chief Information Officer. It collects, organizes, provides for archiving, and disseminates NASA's STI. The NASA STI program provides access to the NASA Aeronautics and Space Database and its public interface, the NASA Technical Reports Server, thus providing one of the largest collections of aeronautical and space science STI in the world. Results are published in both non-NASA channels and by NASA in the NASA STI Report Series, which includes the following report types:

- TECHNICAL PUBLICATION. Reports of completed research or a major significant phase of research that present the results of NASA programs and include extensive data or theoretical analysis. Includes compilations of significant scientific and technical data and information deemed to be of continuing reference value. NASA counterpart of peer-reviewed formal professional papers but has less stringent limitations on manuscript length and extent of graphic presentations.

- TECHNICAL MEMORANDUM. Scientific and technical findings that are preliminary or of specialized interest, e.g., quick release reports, working papers, and bibliographies that contain minimal annotation. Does not contain extensive analysis.

- CONTRACTOR REPORT. Scientific and technical findings by NASA-sponsored contractors and grantees.
- CONFERENCE PUBLICATION. Collected papers from scientific and technical conferences, symposia, seminars, or other meetings sponsored or cosponsored by NASA.

- SPECIAL PUBLICATION. Scientific, technical, or historical information from NASA programs, projects, and missions, often concerned with subjects having substantial public interest.

- TECHNICAL TRANSLATION. Englishlanguage translations of foreign scientific and technical material pertinent to NASA's mission.

Specialized services also include creating custom thesauri, building customized databases, organizing and publishing research results.

For more information about the NASA STI program, see the following:

- Access the NASA STI program home page at http://www.sti.nasa.gov

- E-mail your question via the Internet to help@sti.nasa.gov

- Fax your question to the NASA STI Help Desk at 301-621-0134

- Telephone the NASA STI Help Desk at 301-621-0390

- Write to:

NASA STI Help Desk

NASA Center for AeroSpace Information 7115 Standard Drive Hanover, MD 21076-1320 
NASA/CR-2006-214454

\section{Heat Transfer and Fluid Dynamics Measurements in the Expansion Space of a Stirling Cycle Engine}

Nan Jiang and Terrence W. Simon

University of Minnesota, Minneapolis, Minnesota

Prepared for the

International Mechanical Engineering Congress and Exposition

sponsored by the American Society of Mechanical Engineers

Chicago, Illinois, November 5-10, 2006

Prepared under Grants NAG3-2482 and NCC04GB62G

National Aeronautics and

Space Administration

Glenn Research Center

Cleveland, Ohio 44135 


\section{Acknowledgments}

The work described in this paper was performed for the Science Mission Directorate (SMD) and the Radioisotope Power System (RPS) Program, Exploration Systems Mission Directorate (ESMD) of the Prometheus Program, which provided funding for these projects. We are grateful for sponsorship of this contract by the NASA Glenn Research Center under grants NAG3-2482 and NCC04GB62G. The contract monitors are Dr. Roy C. Tew and Dr. Rodger Dyson. We wish to acknowledge the valuable guidance we received from Dr. Roy C. Tew, Dr. Rodger Dyson, and James Cairelli of the NASA Glenn Research Center.

Trade names and trademarks are used in this report for identification only. Their usage does not constitute an official endorsement, either expressed or implied, by the National Aeronautics and Space Administration.

Level of Review: This material has been technically reviewed by NASA technical management.

Available from

NASA Center for Aerospace Information 7115 Standard Drive

Hanover, MD 21076-1320
National Technical Information Service 5285 Port Royal Road Springfield, VA 22161 


\title{
Heat Transfer and Fluid Dynamics Measurements in the Expansion Space of a Stirling Cycle Engine
}

\author{
Nan Jiang and Terrence W. Simon \\ University of Minnesota \\ Minneapolis, Minnesota 55455
}

\begin{abstract}
The heater (or acceptor) of a Stirling engine, where most of the thermal energy is accepted into the engine by heat transfer, is the hottest part of the engine. Almost as hot is the adjacent expansion space of the engine. In the expansion space, the flow is oscillatory, impinging on a two-dimensional concavely-curved surface. Knowing the heat transfer on the inside surface of the engine head is critical to the engine design for efficiency and reliability. However, the flow in this region is not well understood and support is required to develop the CFD codes needed to design modern Stirling engines of high efficiency and power output. The present project is to experimentally investigate the flow and heat transfer in the heater head region. Flow fields and heat transfer coefficients are measured to characterize the oscillatory flow as well as to supply experimental validation for the CFD Stirling engine design codes. Presented also is a discussion of how these results might be used for heater head and acceptor region design calculations.
\end{abstract}

\begin{tabular}{|c|c|}
\hline \multirow{3}{*}{$\begin{array}{l}c_{p} \\
d_{\text {displacer }}\end{array}$} & Nomenclature \\
\hline & Specific heat \\
\hline & $\begin{array}{l}\text { Characteristic length, taken to be the } \\
\text { displacer diameter }\end{array}$ \\
\hline$h$ & Heat transfer coefficient \\
\hline$k$ & Thermal conductivity \\
\hline$l$ & $\begin{array}{l}\text { Length along head inner surface from } \\
\text { first measuring station, } \mathrm{p} 1 \text {, toward center. }\end{array}$ \\
\hline$l_{h}$ & Total length of the head inner surface \\
\hline$q$ & Wall heat flux \\
\hline$R_{0}$ & Cam offset \\
\hline \multirow{2}{*}{$R e_{\max }$} & \multirow{2}{*}{ Reynolds number, $\frac{U_{\max } d_{\text {displacer }}}{v}$} \\
\hline & \\
\hline$T$ & Temperature \\
\hline$U_{\max }$ & Maximum displacer speed \\
\hline \multirow{2}{*}{$V a$} & \multirow{2}{*}{ Valensi number, $\frac{U_{\max } d_{\text {displacer }}}{v}$} \\
\hline & \\
\hline$X_{\max }$ & Amplitude of the displacer motion \\
\hline$y$ & Distance normal to the head wall \\
\hline$v$ & Kinematic viscosity \\
\hline$f$ & Oscillation frequency \\
\hline$\delta$ & $\begin{array}{c}\text { Boundary layer thickness } \\
\text { Greek }\end{array}$ \\
\hline$\omega$ & Oscillation frequency \\
\hline$\theta$ & $\begin{array}{l}\text { Cam position or position within the } \\
\text { oscillation cycle }\end{array}$ \\
\hline
\end{tabular}

\author{
Subscripts \\ aw Adiabatic wall temperature \\ wall At the wall \\ $\infty \quad$ Outside of the boundary layer
}

Introduction

The research is motivated largely by a desire to improve the understanding of oscillatory fluid mechanics and heat transfer inside a Stirling engine as well as to support the development of multi-dimensional CFD models for design of modern Stirling engines. Focus is given to the expansion region where the flow is separated and transitions from laminar flow to turbulent flow. In this region, such flow features as jets and vortices have been identified. Therefore, experimentation is necessary. In this study, the experiments are conducted to characterize the flow and heat transfer for comparison to computational results.

Adolfson et al. (2003) conducted an introductory investigation of the flow features in the expansion space by utilizing two parallel disks as a simulation of the heater head region. Flow visualization and hot-wire anemometry measurements were performed under conditions of unidirectional flow and oscillatory flow (zero mean velocity). Valuable information was offered by this work towards understanding the fluid mechanics inside a Stirling engine. Unsteady separation and laminar-to-turbulent transition were shown in this study. However, a more accurate simulation of the expansion space geometry is needed and, thus, the present test section, with a more engine-like geometry, was made.

\section{Dimensionless Similarity}

A representative Stirling cycle engine, which has been tested by NASA, was chosen as a pattern engine to study the fluid mechanics and heat transfer characteristics appropriate for a Stirling engine expansion space. First, some parameters of the chosen pattern Stirling engine are introduced.

\section{The Pattern Stirling Cycle Engine Parameters}

Operating conditions and dimensionless parameters of interest for the pattern Stirling engine are listed in Table 1.

A representative cut-away of a Stirling engine of similar geometry to the pattern Stirling engine is shown as Figure 1. Dynamic similarity is used to model the engine aerothermal physics while avoiding the high temperatures and high frequency of the real engine. A large-scale test section is designed and fabricated by matching the non-dimensional numbers: Reynolds number, $\mathrm{Re}_{\max }$, and Valensi number, Va. The maximum Reynolds number, 1150 (see Figure 2), and associated Valensi number, 6650 (see Figure 3), are chosen as representative numbers of the pattern engine. 


\section{Test Section Parameters}

Determining the size of the test section requires considering the minimum measurable velocity. Adolfson et al. (2002, 2003, and 2004) suggested that the lowest velocity that could be accurately measured with a hot-wire is around $0.05 \mathrm{~m} / \mathrm{s}$. This limitation affects the maximum size the test facility could have. The test section design process was by trial and error. A diameter of the displacer of $203 \mathrm{~mm}(8$ inches) was selected. The remainder of the sizes of components (Table 2) came from this selection and the dynamic similitude requirements. Frequency and displacement come by matching the Valensi and Reynolds numbers. Ambient air is the working medium of the test.

Table 1 General Information of the Pattern Engine

\begin{tabular}{|l|l|}
\hline Working fluid & helium \\
\hline Operating temperature & $888 \mathrm{~K}$ \\
\hline Operating pressure & $2.59 \mathrm{MPa}$ \\
\hline Operating frequency & $83 \mathrm{~Hz}$ \\
\hline Kinematic viscosity $(v)$ & $30.1 \times 10^{-6} \mathrm{~m}^{2} / \mathrm{s}$ \\
\hline Reynolds number $\left(\frac{U_{\max } d_{\text {displacer }}}{v}\right)$ & $\begin{array}{c}1150 \\
\text { (see Figure 2) }\end{array}$ \\
\hline Valensi number $\left(\frac{\omega d_{\text {displacer }}^{2}}{4 v}\right)$ & $\begin{array}{c}6650 \\
\text { (see Figure 3) }\end{array}$ \\
\hline
\end{tabular}

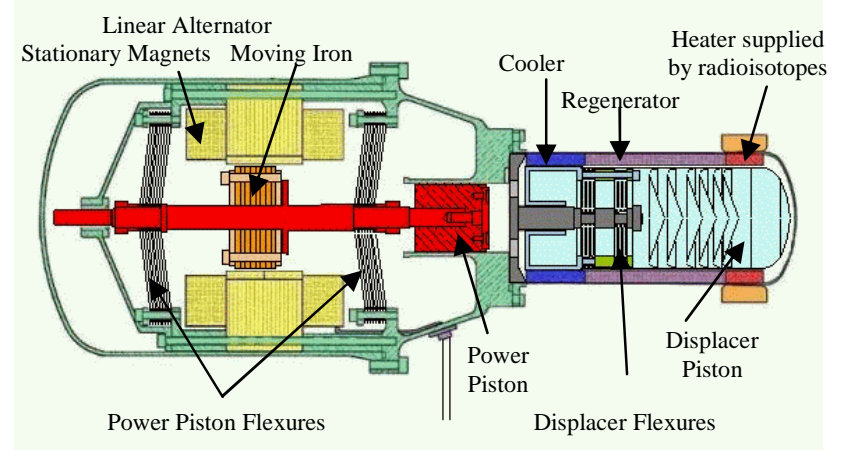

Figure 1 Cut-away of a modern Stirling engine

The maximum displacement of the displacer, $\mathrm{X}_{\max }$, and frequency, $f$, are computed from the dimensionless numbers by using $\mathrm{d}_{\text {displacer }}$ of Table 2 , as follows:

$$
\begin{aligned}
\operatorname{Re}= & \frac{\mathrm{U}_{\text {max }} \times \mathrm{d}_{\text {displacer }}}{v}=\frac{\mathrm{X}_{\text {max }} \times \omega \times \mathrm{d}_{\text {displacer }}}{v}= \\
& \frac{\mathrm{X}_{\max } \times 2 \times \pi \times \mathrm{f} \times(8 . \times 0.0254)}{15.6 \mathrm{E}-6}=1150 \\
\mathrm{Va}= & \frac{\omega \times \mathrm{d}_{\text {displacer }}^{2}}{4 \times v}= \\
& \frac{2 \times \pi \times \mathrm{f} \times(8 . \times 0.0254)^{2}}{4 \times(15.6 \mathrm{E}-06)}=6650
\end{aligned}
$$

$f=1.60 \mathrm{Rev} / \mathrm{sec}=96.0 \mathrm{RPM}$

$X_{\text {max }}=8.78 \mathrm{~mm}(0.35$ inch $)$

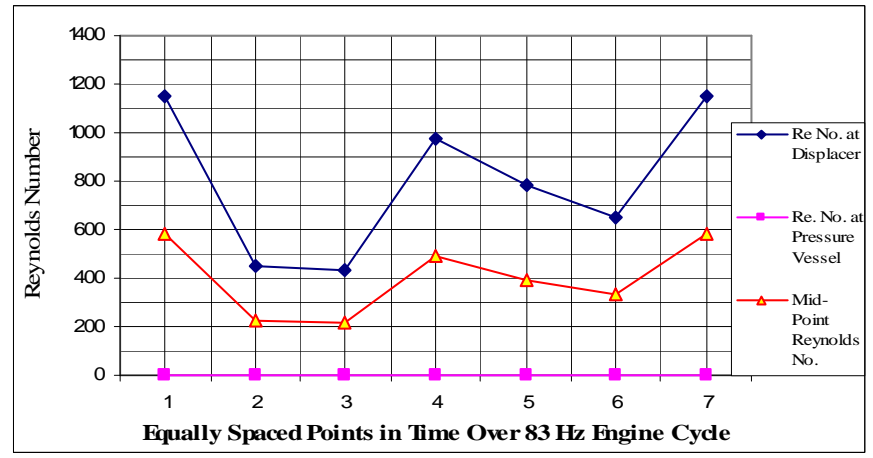

Figure 2 Expansion space Reynolds number based on mean flow velocity and displacer outer diameter

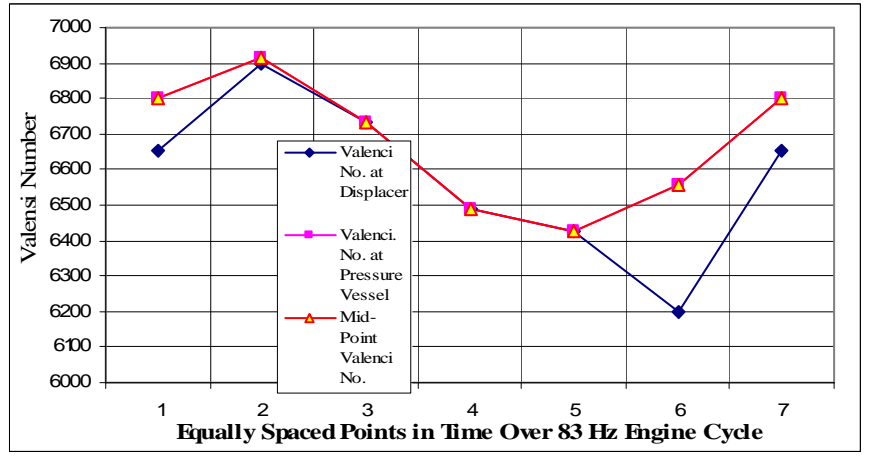

Figure 3 Expansion space Valensi number based on mean flow velocity and displacer outer diameter

Table 2. UMN Test Section Design Parameters mm (inch)

\begin{tabular}{|l|r|}
\hline Displacer diameter & $203(8)$ \\
\hline Regenerator I.D. & $207.9(8.184)$ \\
\hline Regenerator O.D. & $255.0(10.04)$ \\
\hline Inner Regenerator Wall Thickness & $1.29(0.05)$ \\
\hline Outer Regenerator Wall Thickness & $1.76(0.07)$ \\
\hline Appendix Gap Clearance & $1.08(0.04)$ \\
\hline $\begin{array}{l}\text { Minimum Clearance Between Cylinder Head } \\
\text { and Displacer }\end{array}$ & $4.87(0.192)$ \\
\hline Heater Length & $74.6(2.936)$ \\
\hline Heater Channel Width & $3.11(0.122)$ \\
\hline Heater Channel Height & $25.4(1.0)$ \\
\hline Heater Fin Thickness & $6.18(0.243)$ \\
\hline
\end{tabular}

\section{Experimental Facility}

Based upon the above the calculations, a test section, simulating the expansion space and the acceptor region of the pattern Stirling engine and an oscillatory flow generator were designed and fabricated. Both are discussed below.

\section{Oscillatory flow generator}

A cam mechanism (Figure 4) is used to create sinusoidal movement. An eccentrically mounted round plate of $152 \mathrm{~mm}$ (6 inches) diameter rotates to push another round plate, which is placed normal to the rotating cam. A spring is utilized to keep the moving plate always in touch with the rotating plate. Since the vertical plate is always tangent to the round plate, the displacement of the plate, which is here defined to be the 
same as the axial distance from the center of the plate to the center of its rotation, is:

$$
x=R_{0} \cos \theta
$$

The distance between the rotating center and the round plate center, $R_{0}$, is $8.9 \mathrm{~mm}$ ( 0.35 inches), which is half of the required stroke.

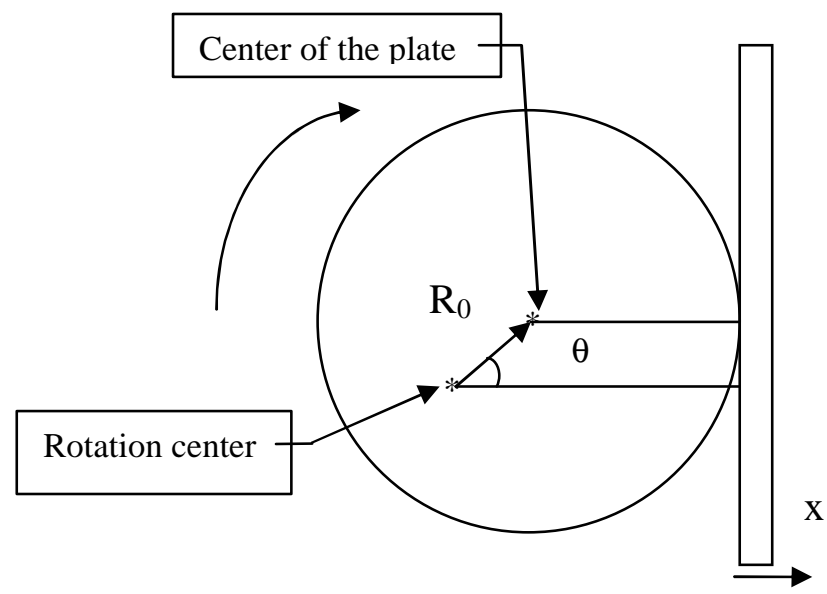

Figure 4 Setup of the cam mechanism

The rotation is driven by a DC Gearmotor (Dayton, Model 4Z381A). The motor is controlled by a DC speed controller (Dayton DC Speed Control, Model 5X412D). The controller supplies a speed range of 0-96 rpm. Figure 5 shows a picture of the test facility.

\section{Flow Resistance and 3-D Flow Path}

To more accurately simulate the flowfield of the real Stirling engine, pressure loss coefficients of the real engine are replicated. A flow resistance is inserted into the regenerator region of the test section to match the characteristics of the actual regenerator pressure drop and achieve the proper balance between pressures and inertial forces of the pattern engine. A heater simulator is constructed by scaling the acceptor of an actual engine. This generates the 3-dimensional flow expected in the engine path. The flow resistance and the acceptor are discussed in the following section.

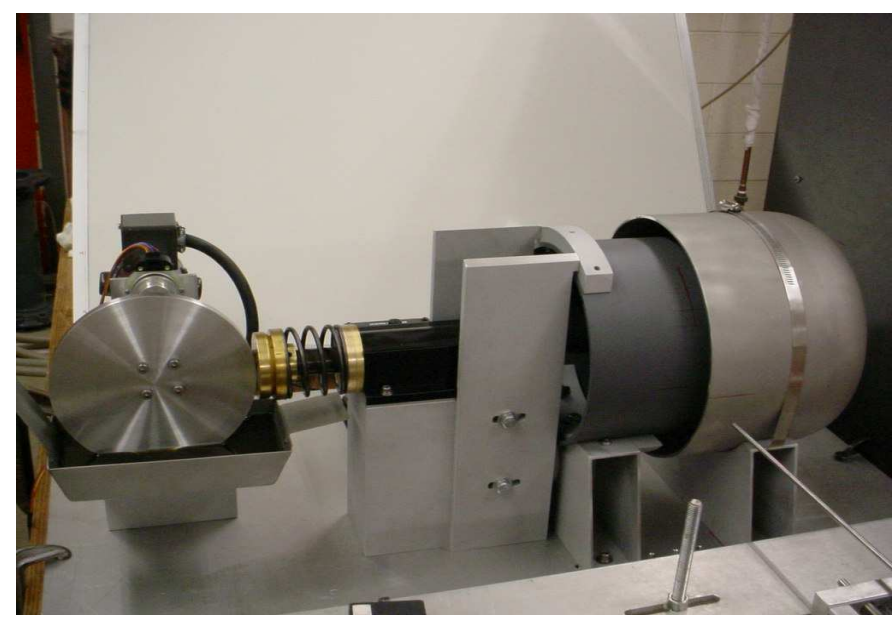

Figure 5 Test facility

\section{Flow resistance simulation}

The regenerator in the Stirling engine is a porous medium. To duplicate the pressure drop, a similar porous medium is inserted into the annular gap of the test section (shown in Figure 6). The resistance caused by the porous medium is representative of the flow resistance caused by a regenerator and a heat exchanger unit (cooler) in the engine. A $3 \mathrm{M}$ stripper pad 7200 (see Figure 7) is chosen for this matching. It occupies all the space between the tubes. Separate experiments verify a match with the actual engine.

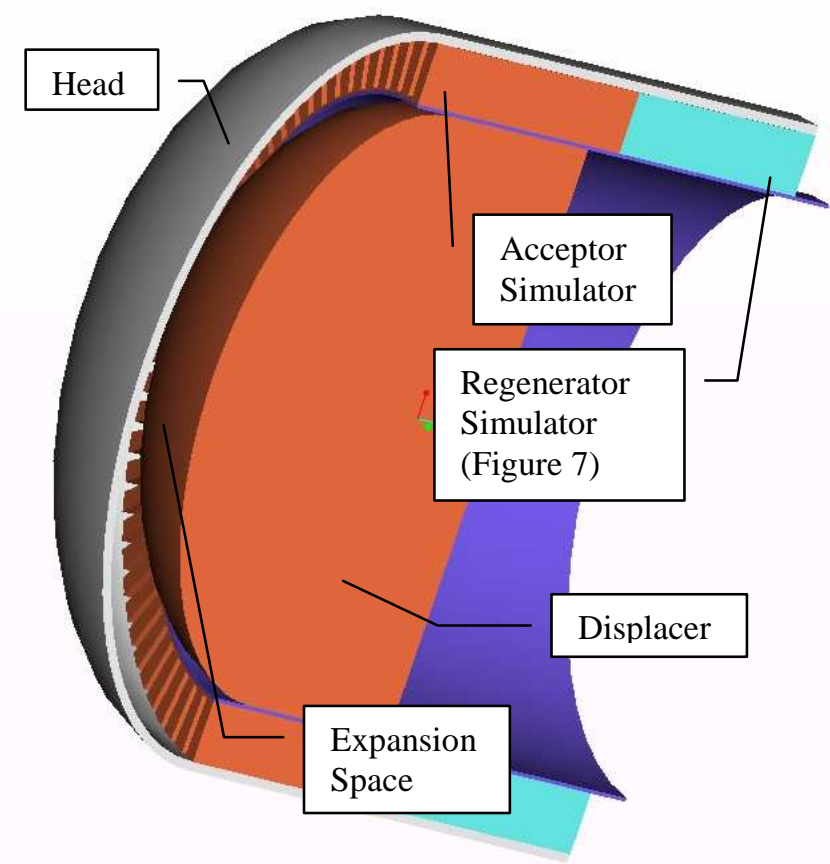

Figure 6 The set-up of flow resistance and flow path

\section{Acceptor simulator}

The acceptor simulator shown in Figure 8 was constructed to generate the 3-D features of the flow from the regenerator to the test section. It is based on the information in Table 3. There are 77 discrete rectangular slots.

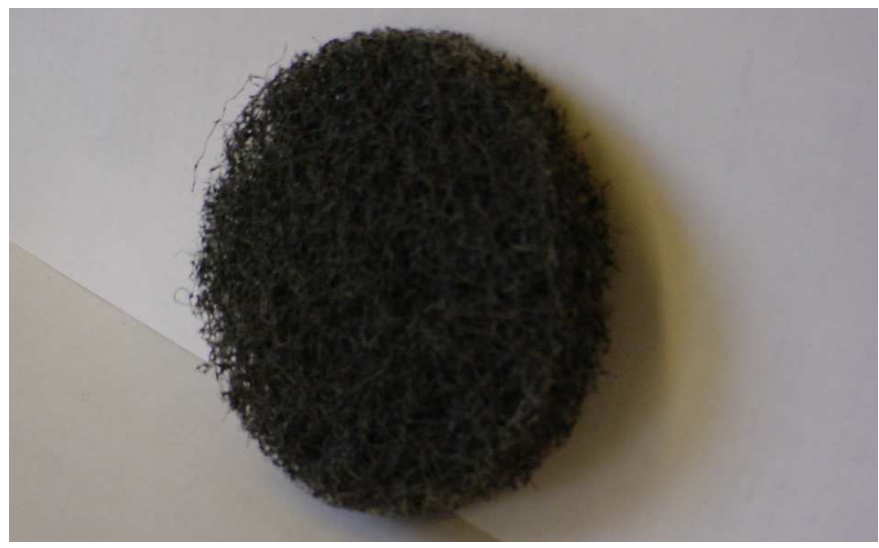

Figure 7 3M stripper pad 7200 


\section{Experimental setup}

\section{Setup for Flow Visualization}

To see the flow inside the test section, a clear acrylic head was made for flow visualization. It replaces the stainless steel head used for the velocity and heat transfer measurements. Figure 9 shows the setup for the flow visualization test. Smoke is fed to the near outer-wall region of the head through a thin, bent tube which passes through the regenerator simulator (porous insert). The smoke is fed directly to the region to be observed. Other means of feeding smoke were tried and the setup described was selected. A laser beam is shined through a glass rod to make a light sheet to illuminate the area of interest.

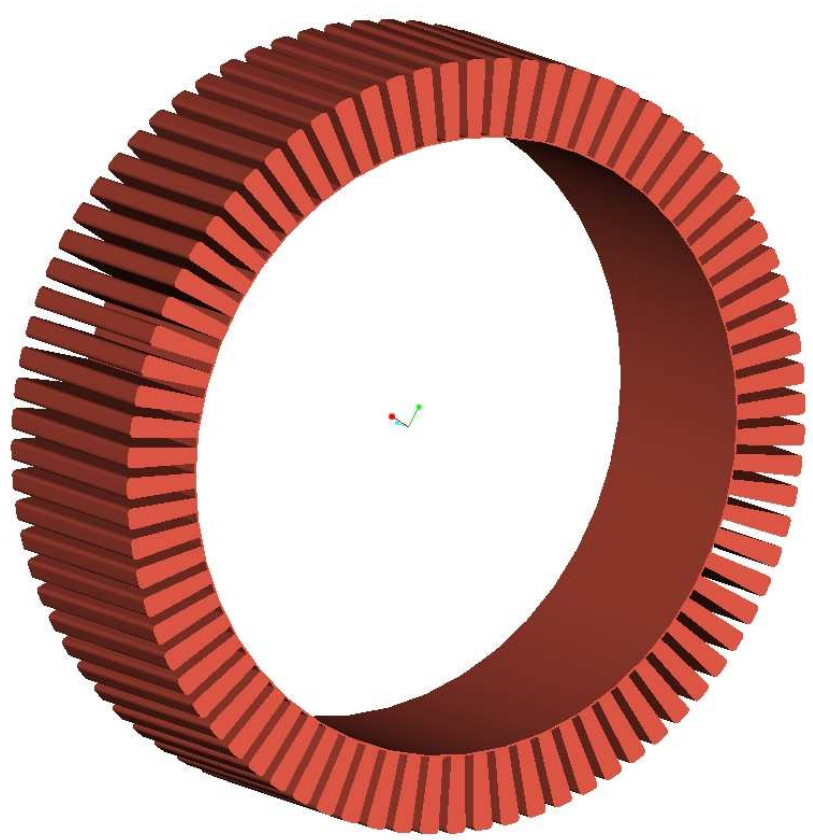

Figure 8 Acceptor simulator

A digital camcorder is used to record the unsteady flowfield. Both video and frames saved as still pictures were found to be useful for visualizing the flow at different times within the cycle.

In the movies and stills, $\theta$ is used as the value of the angle that the short axis of the cam (eccentric circular plate) makes with the horizontal line (see Figure 4). The gap between the head and the displacer is minimum when $\theta=0^{\circ}$.

Table 3 Dimensions of acceptor simulator, units: $\mathrm{mm}$ (inch)

\begin{tabular}{|l|l|}
\hline $\begin{array}{l}\text { Outer } \\
\text { Diameter }\end{array}$ & $243.08(9.57)$ \\
\hline $\begin{array}{l}\text { Inner } \\
\text { Diameter }\end{array}$ & $206.88(8.145)$ \\
\hline Length & $74.6(2.936)$ \\
\hline Slot width & $3.11(0.122)$ \\
\hline Slot height & $17.97(0.7075)$ \\
\hline Fin width & $6.18(0.243)$ \\
\hline
\end{tabular}

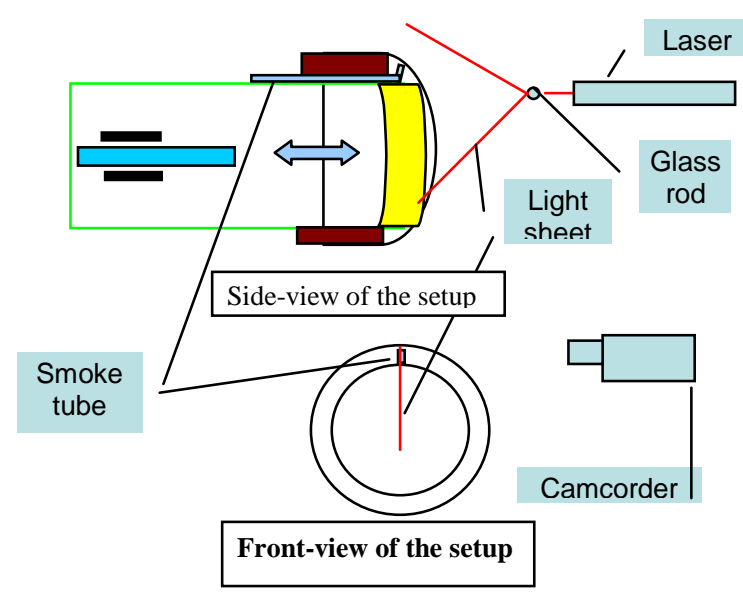

Figure 9 Setup of flow visualization

\section{Setup for Velocity Measurements}

Of interest is the unsteady flow field between the displacer and the inside surface of the head, including the boundary layer on the inside surface of the head. Because of the movement of the displacer, the size of this space is changing. Measurements can be taken only in the head-todisplacer space available at $\theta=0^{\circ}$.

As can be seen in Figure 6, the measurement space is a fully closed region. Thus, eight holes are drilled for probe access. A guiding system was developed for positioning the hotwire probe. The flow is nominally axisymmetric (aside from the fine-scale circumferential variations due to the features of the acceptor simulator). Thus, to reduce interaction of the holes with the flowfield, measuring stations are distributed at various circumferential positions, as shown in Figure 10.

The velocity is measured at $\mathrm{p} 1$ through $\mathrm{p} 7$ (see Figure 10 and Table 4). For each measuring station, there are 25 measurement positions normal to the head wall surface for $\mathrm{p} 1$ - p5, 23 for p6, and 22 for p7. For each position, measurements are taken for 150 cycles, and then ensembleaveraged velocities are calculated.

\section{Setup of Temperature Measurement}

The thermal field in the real engine is complicated and cannot be duplicated in the current test section. The objective of the present thermal study is to measure the convective heat transfer coefficient distribution on the inside surface of the head. The convective heat transfer coefficient is determined predominantly by the fluid dynamics, in this highly agitated flow and is expected to be only weakly affected by thermal boundary conditions.

Figure 11 shows the thermal setup of the test section. A heating element, Chromalox HSP-2.75, is glued on the center of the head by using an epoxy of good conductivity. The input voltage of the heating element is set to $20 \mathrm{AC}$ volts. A copper tube, $6.35 \mathrm{~mm}(1 / 4 \mathrm{inch})$ O.D., is wrapped on the outer surface of the head where the acceptor simulator is located inside and glued using epoxy for good contact with the head surface. City water flows though the copper tube. Contact between the acceptor simulator and the inside surface of the head is enhanced by using woods metal. The woods metal is heated to liquid and then put in the gap between the acceptor and the inside head wall before it cools to become a solid. Therefore, 
heat transfer from the acceptor simulator to the cold tube is effective. When the internal air flow passes through the acceptor simulator, it is cooled uniformly because the acceptor simulator acts as an effective heat exchanger. The entire head is then wrapped using insulation material to reduce heat transfer to the ambient. Figure 12 shows the wall temperatures at the various measuring stations with the current setup.

Table 4 Measuring station locations

\begin{tabular}{|l|l|l|l|}
\hline $\begin{array}{l}\text { Measuring } \\
\text { Stations }\end{array}$ & $\begin{array}{l}\text { S mm } \\
\text { (inch) }\end{array}$ & $\theta$ & $\begin{array}{l}\text { R mm } \\
\text { (inch) }\end{array}$ \\
\hline P0 & $\begin{array}{l}14.1 \\
(0.556)\end{array}$ & $0^{\circ}$ & $\begin{array}{l}124 \\
(4.87)\end{array}$ \\
\hline P1 & $\begin{array}{l}17.2 \\
(0.678)\end{array}$ & $5^{\circ}$ & $\begin{array}{l}122 \\
(4.81)\end{array}$ \\
\hline P2 & $\begin{array}{l}27.7 \\
(1.09)\end{array}$ & $10^{\circ}$ & $\begin{array}{l}114 \\
(4.50)\end{array}$ \\
\hline P3 & $\begin{array}{l}34.7 \\
(1.37)\end{array}$ & $20^{\circ}$ & $\begin{array}{l}106 \\
(4.19)\end{array}$ \\
\hline P4 & $\begin{array}{l}43.7 \\
(1.72)\end{array}$ & $30^{\circ}$ & $\begin{array}{l}92.1 \\
(3.62)\end{array}$ \\
\hline P5 & $\begin{array}{l}48.9 \\
(1.93)\end{array}$ & $40^{\circ}$ & $\begin{array}{l}81.0 \\
(3.19)\end{array}$ \\
\hline P6 & 43.7 & $50^{\circ}$ & $\begin{array}{l}66.7 \\
(2.62)\end{array}$ \\
\hline P7 & 57.8 & $60^{\circ}$ & $\begin{array}{l}52.4 \\
(2.06)\end{array}$ \\
\hline
\end{tabular}

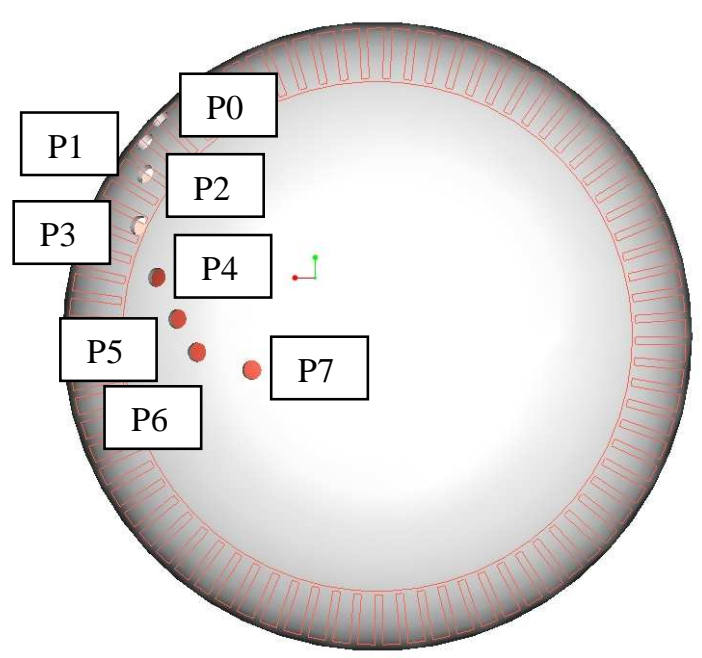

Figure 10 Locations of measuring stations

The access system and measuring stations used for velocity measurements are used also in the temperature measurements. Station P0 is used for monitoring the temperature in the center of an acceptor slot and very near the plane of the acceptor which is nearest the head. This temperature is used as a reference temperature. For each position, the measurements are taken for 200 cycles then ensemble-averaged temperature profiles are calculated.

\section{RESULTS}

\section{Results of the flow visualization study}

The purpose of the flow visualization is to have a general sense of the flow field before the detailed measurements are taken. The measurements are planned accordingly. As discussed, the measurements are taken assuming that the flow is two-dimensional. Flow visualization is able to show 2-D or 3-D flow features which might not be easily identified by looking at the measurement results only. Also the flow direction, which cannot be measured by a single hot-wire sensor, can be determined with the help of flow visualization.

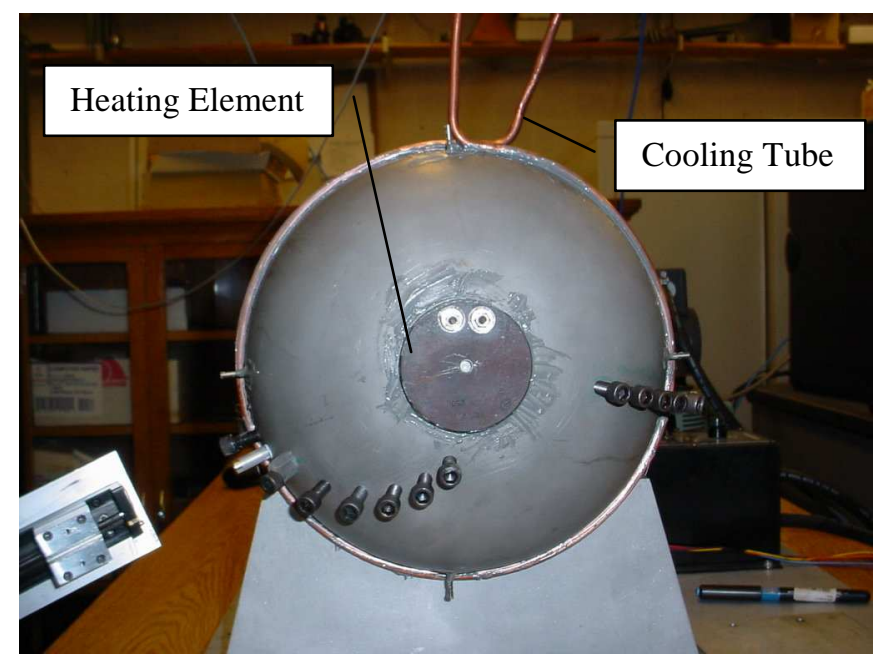

Figure 11 Setup of thermal boundary of the test section

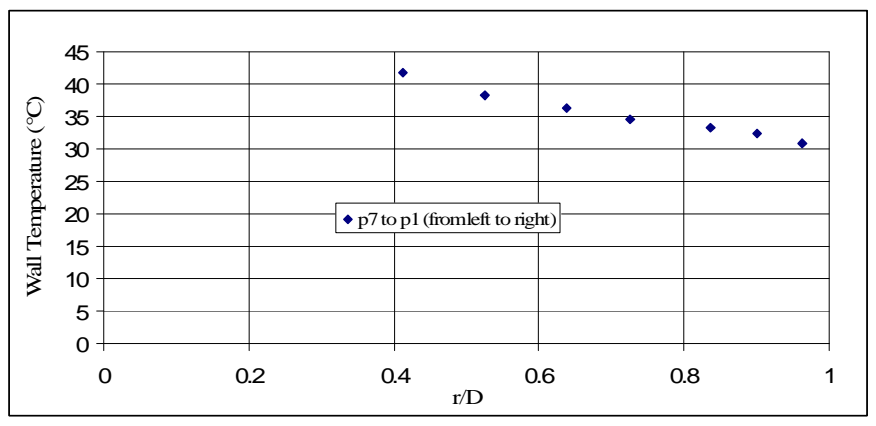

Figure 12 The wall temperature distribution

In general, the flow field is axisymmetric and is generated by the sinusoidal movement of the displacer. In the exhaust half cycle, the displacer pushes the air toward the head and out the acceptor. The flow is impinged upon the head surface and then turns and flows out of the test section along the head curved surface. In the drawing half cycle, the displacer moves away from the head and the air is drawn into the test section through the acceptor. The air flows in along the head surface first and then turns toward the axial direction and follows the movement of the displacer.

By watching the flow visualization videos, we observe that a vortex (visible in Figure 13) is generated just to the left (in the picture) of where the acceptor plane (opposite the regenerator) resides. This frame was taken at about the end of the exhaust part of the cycle $\left(\theta=360^{\circ}\right)$ or about when the displacer top is nearest the engine head. The vortex drives flow near the acceptor toward the displacer. It is generated by the pressure field established during the exhaust half-cycle by the opposing movements of the bulk flow (upper region in the 
picture) and the flow near the displacer. The flowfield is nonuniform in the knuckle region where the head wall curvature is strongest. The flow near the head inside surface (upper part of the picture) has high velocities while the flow close to the displacer wall (lower part of the picture) has lower velocities. The flow immediately adjacent to the head inner wall is slow and seems to be separated. At the end of the exhaust portion of the cycle, the straight wall of the displacer extends beyond the shroud and creates a moving wall. The moving wall drags the near-by flow in the opposite direction to the bulk flow. This fluid motion might be expected to result in non-uniform flow into the acceptor. When the displacer reverses direction and the drawing portion of the cycle begins, the vortex dissipates.

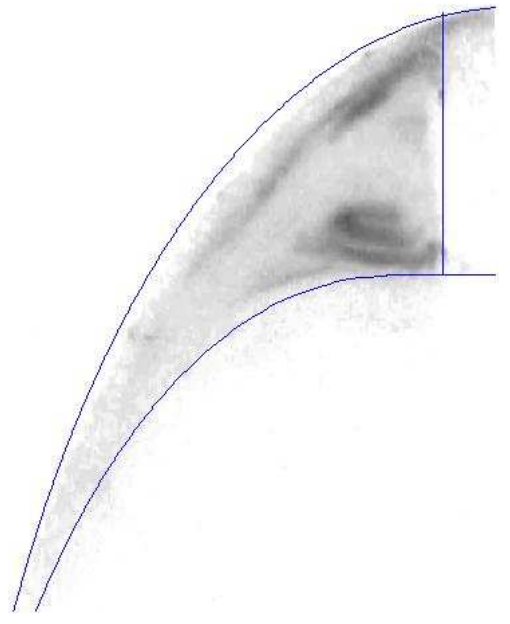

Figure 13 Flow visualization in the space between the displacer and the head at $\theta=360^{\circ}$

\section{$\underline{\text { Results of Velocity Measurements }}$}

Velocity measurements show that the flowfield has a thick separation region on the entire head surface during the whole cycle. For the drawing half cycle, the separation region is caused by the flow moving away from the head due to the displacer motion. Separation during the exhaust half cycle was observed also by Gilard and Brizzi (2005). They were investigating the slot jet impinging on a concave curved wall. When they reduced the ratio of the curvature diameter and the slot diameter, a "dead fluid" region was found in the region near the curved wall center. The flow was forced to turn without following the wall. It is felt that the separation zone is caused by local flow deceleration associated with the introduction of concave curvature. This local spatial deceleration due to curvature is present regardless of flow direction. Thus, separation is observed during both the exhaust portion of the cycle and the drawing portion of the cycle.

The thickness of the separation region changes during the cycle, however. When the free-stream velocity is large, the separation thickness is smaller and when the free-stream velocity is small, the separation zone is thicker. Also, the separation zone is thicker during the exhaust portion of the cycle $\left(180^{\circ}<\theta<360^{\circ}\right)$ than during the drawing portion of the cycle $\left(0^{\circ}<\theta<180^{\circ}\right)$. This can be seen in the velocity traces of Figure 14. Note that the high-velocity region at $\theta=90^{\circ}$ is nearer to the wall than the high-velocity region at $\theta=270^{\circ}$. This is generally true for all measurement stations. The separation thickness is larger at station p7 (nearer the top of the head) than at station p1 (nearer the acceptor).

In Figure 14, and others, we can see high-frequency velocity changes, e.g. $70^{\circ}<\theta<140^{\circ}$. This is not inherent in the engine flow but a product of the gear tooth geometry in the drive mechanism of the test facility. The driven gear rotational speed is not precisely constant, though the driving gear is. This is done by the gear train designer to reduce tooth stresses. It is an unattractive feature of this test. The overall effect is considered to be negligible, however.

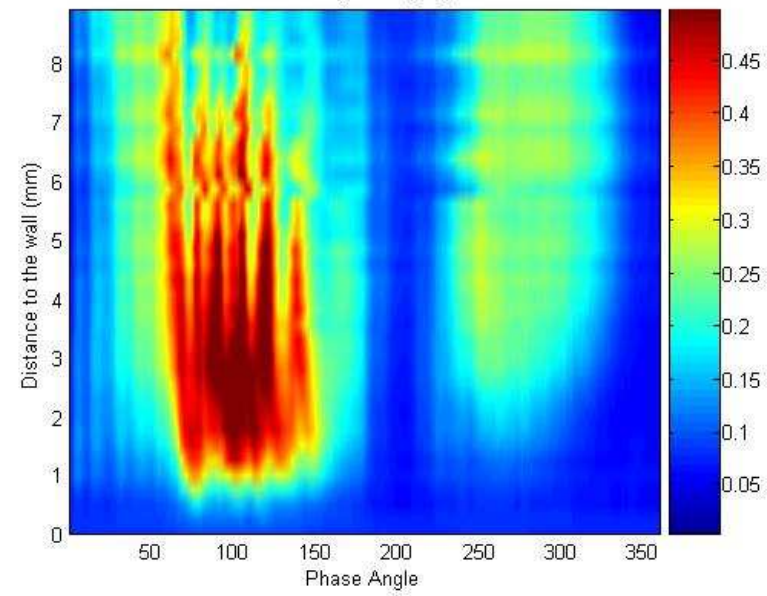

Figure 14 Velocity $(\mathrm{m} / \mathrm{s})$ vs. phase angle at P2

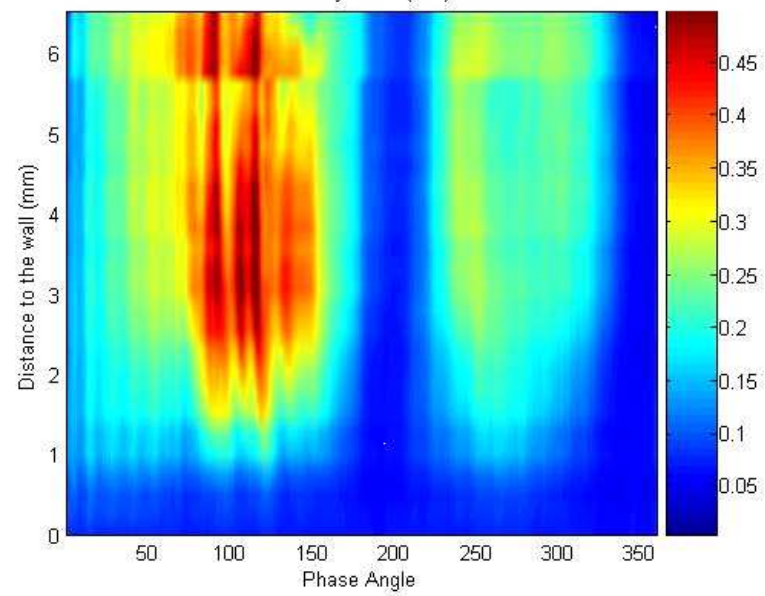

Figure 15 Velocity $(\mathrm{m} / \mathrm{s})$ vs. phase angle at P3

In the drawing half cycle, the displacer moves back from the head. The flow is drawn into the test section. The flow exits from the acceptor discrete slots as a series of jets (see Figure 16a). Between the slots of the acceptor, the flow velocity in the test section is small. Thus, during the drawing half cycle, the flow is non-uniform near the acceptor plane exit. During the exhaust half cycle, the flow is blown out of the test section. The velocity is very uniform until it reaches the slots of the acceptor. Then the flow accelerates into the slots. Thus, during the exhaust half cycle, the flow is more uniform, but has lower velocities. This explains why the velocities in the measurement zone during the first half cycle generally are larger than the velocities during the second half cycle for measuring stations near the acceptor (see Figures 14 and 15).

Another interesting feature captured by the measurements is that the peak velocity region of the drawing half cycle $\left(0^{\circ}<\right.$ $\theta<180^{\circ}$ ) moves. At p1 (Figure 17), the peak velocity is shown in the period of $60^{\circ}<\theta<110^{\circ}$ in time and $1 \mathrm{~mm}$ away from the wall while at p2 (Figure 14), the center of the peak velocity region moves to $\theta=100^{\circ}$. The movement of the peak 
velocity region is more obvious at $\mathrm{p} 3$ (Figure 15). The center of the peak velocity region is at $\theta=125^{\circ}$ and $1.5 \mathrm{~mm}$ away from the wall. The movement of the peak velocity region suggests convection of flow features such as the vortex mentioned in the flow visualization section of this paper. This vortex was observed to be unsteady. The single hot-wire sensor can record only the velocity magnitude.

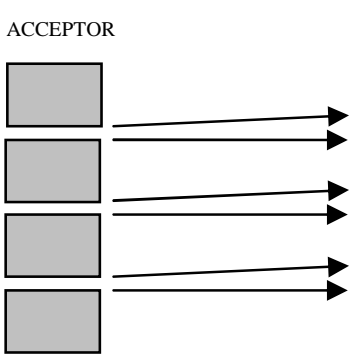

(a)

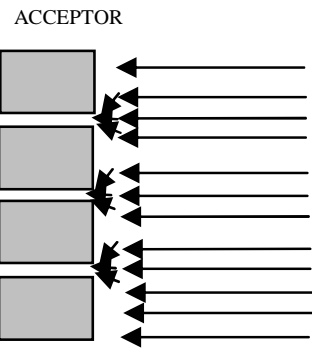

(b)
Figure 16 The flow patterns at different parts of the cycle (a) Jets flow during the drawing half cycle (b) A sink flow is observed during the exhaust half cycle

\section{Results of Temperature and Heat Transfer Coefficients} Measurements

The objective of the thermal measurement program is to determine the convective heat transfer coefficients. Ensembleaveraged temperature profiles are presented in this section. Using the temperature profiles, heat flux, heat transfer coefficients, and Stanton numbers are computed.

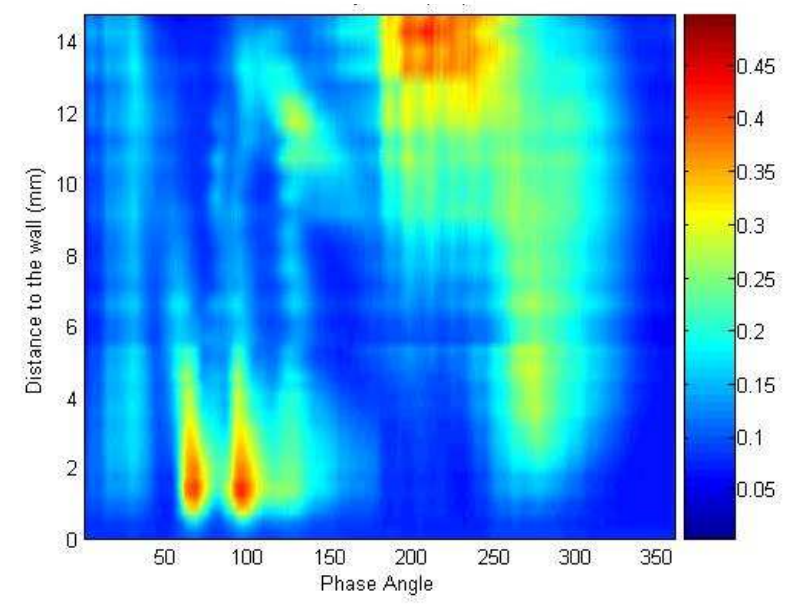

Figure 17 Velocity $(\mathrm{m} / \mathrm{s})$ vs. phase angle at P1

Both the thermocouple probe and the cold-wire probe are used for temperature measurements. However, because of the low velocities, the response of the thermocouple is not fast enough to capture the temperature changes in the flow, which has an oscillation frequency of about $1.6 \mathrm{~Hz}$. The only thermocouple measurements used are those taken near the wall. They help determine the heat flux. This will be discussed later in the section.

\section{Results of the temperature measurements}

The temperature profiles are used also to help study the fluid dynamics, for the thermal signal acts as a tracer. The thermal signature movement can be correlated with the same features affecting the velocity measurements. During the drawing half cycle, one would expect that the cold flow from the acceptor comes into the test section and the temperature drops. But, at p1, p2, and p3, the flow temperature is higher than the wall temperature (see Figures 18, 19, and 20). This means that some of the heated flow remains in the test section during the exhaust half cycle. Recall the vortex shown in the flow visualization and that this vortex occurs in the region of p1. In the exhaust half cycle, the flow is generally heated and pushed out of the test section. The flow temperatures at $\mathrm{p} 1$ and p2 rise (see Figures 18 and 19). During the exhaust half cycle, the flow temperatures in the free-stream at p3, p4, p5, p6, and p7 decrease (see Figures 20-24). That is because of heat transfer with the displacer. The flow, cooled by the displacer, is passing by the probe.

In general, the thermal boundary layer near the center of the head at p4, p5, p6, and p7 is thicker than that near the knuckle region at p1, p2, and $\mathrm{p} 3$, which agrees with the momentum boundary layer thickness evaluations from the velocity measurements.

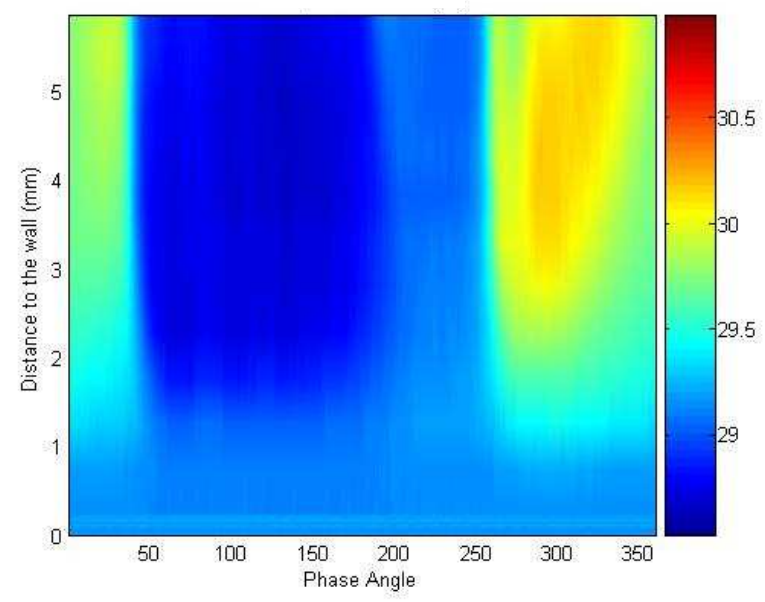

Figure 18 Temperature $\left({ }^{\circ} \mathrm{C}\right)$ vs. phase angle and distance from the wall, $y$ at $\mathrm{P} 1$

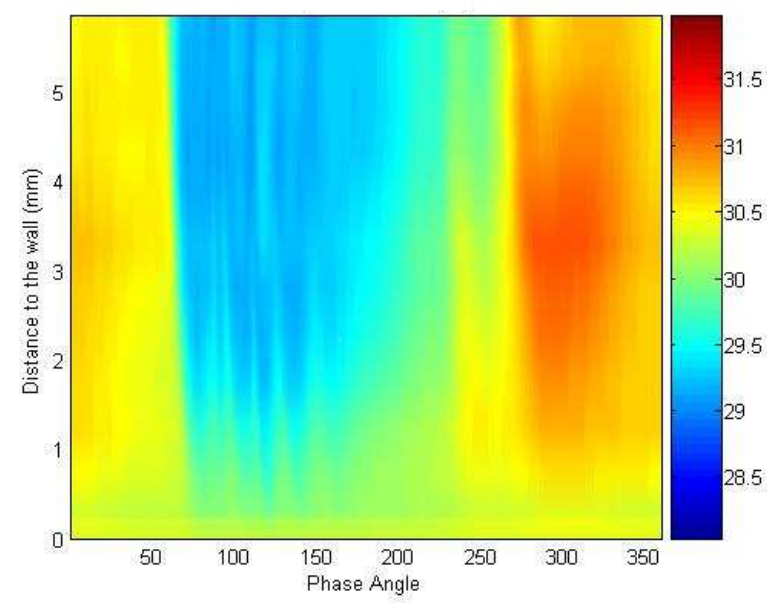

Figure 19 Temperature $\left({ }^{\circ} \mathrm{C}\right)$ vs. phase angle and distance from the wall, $y$ at $\mathrm{P} 2$ 


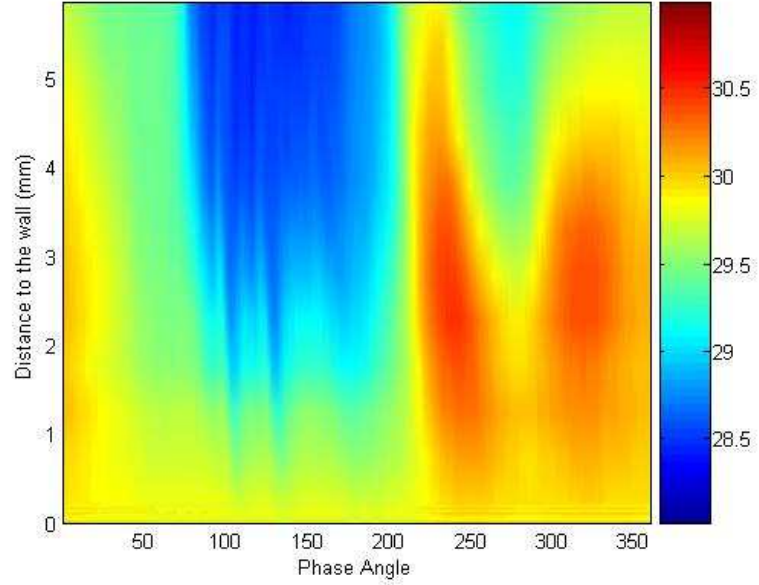

Figure 20 Temperature $\left({ }^{\circ} \mathrm{C}\right)$ vs. phase angle and distance from the wall, $y$ at P3

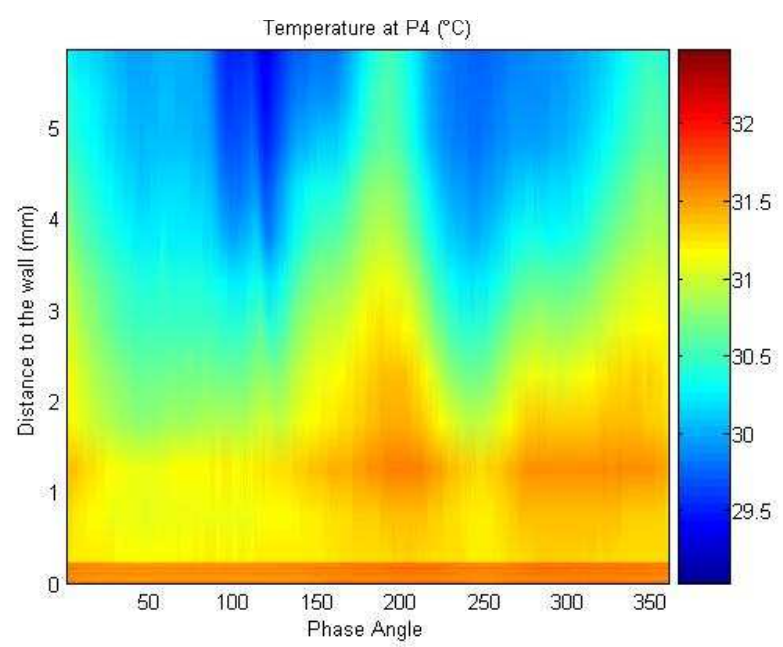

Figure 21 Temperature $\left({ }^{\circ} \mathrm{C}\right)$ vs. phase angle and distance from the wall, $y$ at $\mathrm{P} 4$

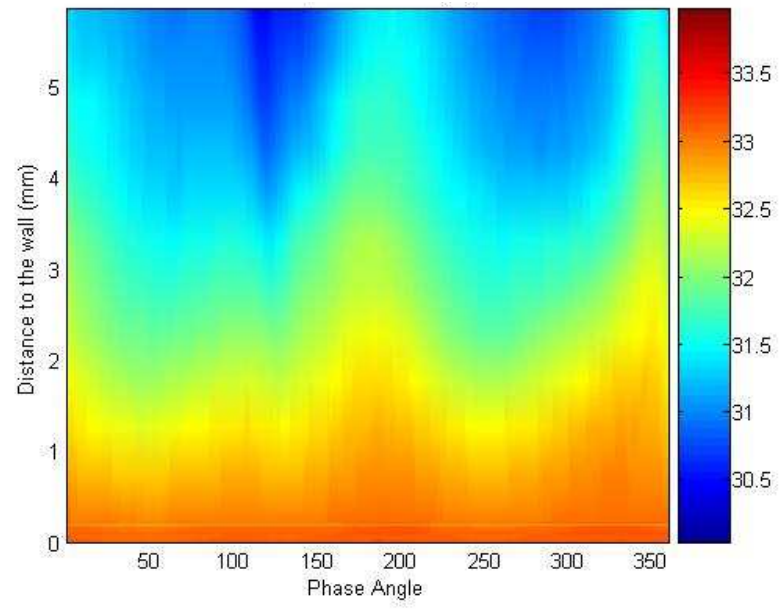

Figure 22 Temperature $\left({ }^{\circ} \mathrm{C}\right)$ vs. phase angle and distance from the wall, $y$ at P5

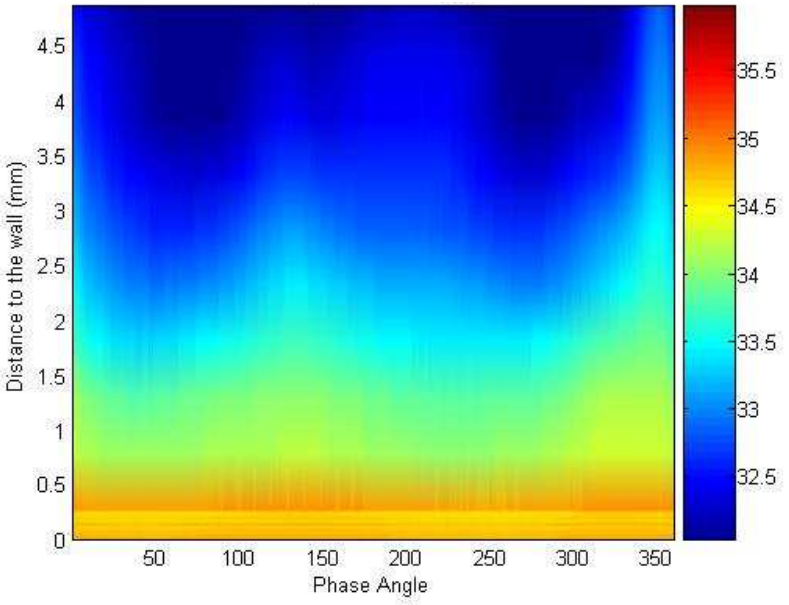

Figure 23 Temperature $\left({ }^{\circ} \mathrm{C}\right)$ vs. phase angle and distance from the wall, y at P6

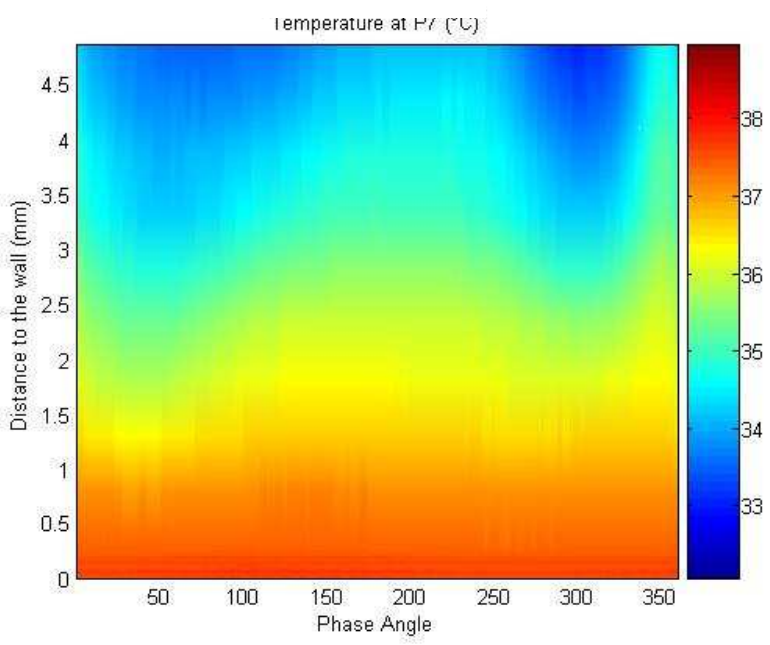

Figure 24 Temperature $\left({ }^{\circ} \mathrm{C}\right)$ vs. phase angle and distance from the wall, y at P7

\section{Results of heat transfer coefficient measurements}

The heat transfer coefficient, $h$, is the key parameter to be evaluated. It is assumed that it is primarily dependent on the fluid mechanics and only secondarily dependent on the thermal boundary conditions. This assumption will be discussed more thoroughly below. This is expected for wellmixed flows. There are questions about the robustness of this assumption in separated flows. Within the separation zone, we must be content to just state that heat transfer coefficient, $\mathrm{h}$, is very low.

Measurements of the heat transfer coefficients are based on the fact that there is a conduction region near the wall, the inner part of the boundary layer (called the conduction layer), where the flow velocity is low and wall-normal transport is by molecular conduction only. The temperature profile near the wall region is carefully measured with high spatial resolution. The slope of the linear gradient of the temperature in the nearwall region is used to calculated the heat flux by using the following equation: 
$\dot{q}=-k \frac{d T}{d y}$

Through the measured temperature profile, we can get the wall temperature and the free-stream flow temperature. Therefore, the heat transfer coefficient is calculated as:

$h=\frac{\dot{q}}{T_{\text {wall }}-T_{\infty}}=\frac{-k \frac{d T}{d y}}{T_{\text {wall }}-T_{\infty}}$

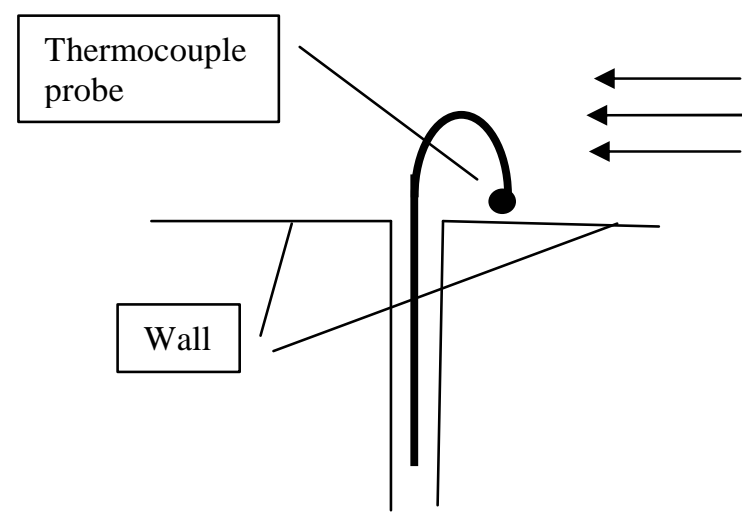

Figure 25 Schematic of the setup for the thermocouple measurements

\section{Heat flux}

A thermocouple probe was the first thermal probe used in this study. Figure 25 shows the schematic of the setup with this probe. The probe is drawn toward the wall until the tip touches the wall. Then the probe is traversed away from the wall with very small steps. Electrical continuity with the wall is used to determine when the thermocouple tip departs from the wall. The wall location uncertainty is $50 \mu \mathrm{m}$.

Measurements from this thermocouple probe of temperature profiles in the near-wall region are sufficiently accurate for processing of heat flux. However, it is found that the time constant of the thermocouple probe is too large; it cannot capture the temperature change in the free-stream which has significant amplitude of change with a frequency of more than $2 \mathrm{~Hz}$. This brings up the problem of calculating the heat transfer coefficients, which requires the free-stream temperature values. Instead of the thermocouple probe, a coldwire probe is substituted. The cold-wire probe is a hot-wire probe operated as a resistance temperature detector. Data from the traversing cold-wire probe were found to be useful for computing all components of the heat transfer coefficients in the thick boundary layers. The thermocouple measurements near the wall are used only to help determine the linear temperature gradients in the near-wall region by comparing to the cold-wire measurements.

Figure 26 shows the ensemble-averaged heat flux distributions on the wall surface during the cycle. The heat flux is set to be positive if the heat transfer is from the flow to the wall; it is negative if the heat transfer is from the wall to the flow. At p1, p2, and p3, the heat transfer is from the flow to the wall in the periods of $0^{\circ}<\theta<50^{\circ}$ and $250^{\circ}<\theta<360^{\circ}$. During the rest of the cycle, the heat transfer is from the wall to the flow. At p4, p5, p6, and p7, the heat transfer is from the wall to the flow during the entire cycle. The maximum magnitude of heat flux appears at $\mathrm{p} 7$. In general, the heat flux drops from $\mathrm{p} 7$ to $\mathrm{p} 1$, which agrees with the thermal setup. However, at $\mathrm{p} 2$, in the periods of $75^{\circ}<\theta<175^{\circ}$ and $275^{\circ}<\theta$ $<340^{\circ}$, the heat flux is larger than at p1 and p3. That is because $\mathrm{p} 2$ is a location of strong wall curvature.

\section{Adiabatic wall temperature}

To calculate heat transfer coefficients by using Eqn. (3), we must determine the wall temperature and the free-stream temperature (or sink temperature) from the measured temperature profiles. The wall temperature is consistent and obvious from the measurements. We use the temperature at first point (nearest to the wall) as the wall temperature. This agrees with values from embedded thermocouples.

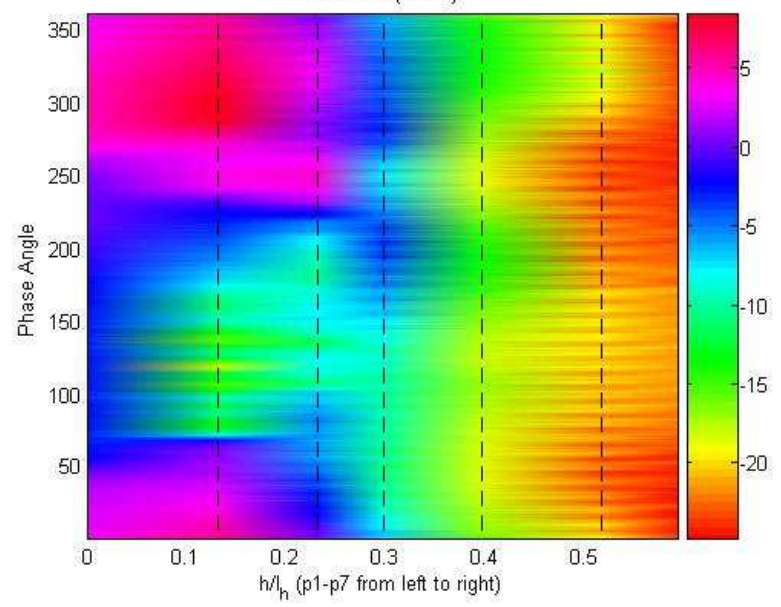

Figure 26 Ensemble averaged heat flux $\left(\mathrm{W} / \mathrm{m}^{2}\right)$ (Dashed line shows the measuring station locations)

The sink temperature (free-stream temperature) is not easy to determine due to the curved surface and mixing of flow. Figure 27 shows the temperature profile at $\theta=328^{\circ}$ of $\mathrm{p} 3$, as an example. The free-stream temperature profile is not uniform at this time. The flow closer to the wall has a higher temperature than the flow far away from the wall. It is obvious that the temperature difference between the wall and the flow adjacent of the thermal boundary layer, in the region of 2.3 $\mathrm{mm}<\mathrm{y}<3.3 \mathrm{~mm}$, drives the heat transfer between the flow and the wall. Therefore, we next introduce the free-stream temperature profile and propose the adiabatic wall temperature as the sink temperatures for evaluating heat transfer coefficients, as will be discussed.

The free-stream temperature profile is defined as the temperature distribution beyond the thermal boundary layer's edge. Taking the example at p3, we select temperatures beyond $\mathrm{y}=2.3 \mathrm{~mm}$ for the free-stream temperature distribution and select the temperature at $\mathrm{y}=2.3$ as the freestream temperature (see Figure 27).

The adiabatic wall temperature is the wall temperature that would be if there were no heat transfer between the wall and the flow at the point of interest. Eckert (1984) found that a 
heat transfer coefficient based on the adiabatic wall temperature in film cooling experiments depends only on the fluid mechanics. With film cooling, a jet of cool fluid is introduced into the thermal boundary layer of interest. The film cooling flow mixes with the mainstream flow, similar to the way in which the mainstream flow is mixing with the heated flow being convected from other heated regions in the present study. In a typical film cooling study, the adiabatic film cooling temperature is measured first in a test with an adiabatic wall. Then the heat transfer coefficient is measured, using that adiabatic wall temperature as the sink temperature. However, due to the thermal setup of the current experiment, we cannot measure the adiabatic wall temperature in an experiment which has an adiabatic wall. Instead, we find the flow region which is responsible for the local heat transfer between the wall and the flow and define the thermal boundary layer to be that region. We use measurements of velocity to identify the momentum boundary layer thickness to aid in this determination. We then extrapolate the temperature profile of the flow external to the thermal boundary layer, as shown by example below. The extrapolated temperature on the wall is defined as the adiabatic wall temperature. It is the temperature the wall would have if that section at the wall were not heated. Figure 27 shows an example of how we get the adiabatic wall temperature. From the velocity profiles, we identify the boundary layer thickness, in this case $\delta=2.0 \mathrm{~mm}$. We assume that the thermal boundary layer is approximately of the same thickness. We use this to locate points just outside of the conduction layer in the measured temperature profile (three points in the range $2.3 \mathrm{~mm}<\mathrm{y}<3.3 \mathrm{~mm}$ in this example) and extrapolate the slope they make to the wall to determine the adiabatic wall temperature.

The heat transfer coefficient based on adiabatic wall temperature is defined as:

$h_{a w}=\frac{\dot{q}}{T_{\text {wall }}-T_{a w}}=\frac{-k \frac{d T}{d y}}{T_{\text {wall }}-T_{a w}}$

Figure 28 shows such heat transfer coefficients based upon the adiabatic wall temperatures. These are expected to depend predominately on the flow field and be insensitive to the thermal boundary conditions. Values of $h$ (or nondimensionalized $h$ ) that are based upon $\mathrm{T}_{\mathrm{aw}}$ are transportable to the real engine for evaluation of convective heat transfer.

Figure 29 shows heat transfer coefficients computed with $T_{\infty}$, the temperature in the flow external to the thermal boundary layer. We would expect these $h$ values to be more dependent upon the thermal boundary conditions.

At each location, it is found that the heat transfer coefficients cannot be determined at some times within the cycle, e.g. $\theta=40^{\circ}$ and $\theta=250^{\circ}$ for $\mathrm{p} 1, \theta=60^{\circ}$ for $\mathrm{p} 2,0^{\circ}<\theta$ $<50^{\circ}$ for $\mathrm{p} 3$ and etc. That is because during these parts of the cycle, the temperature differences and the heat fluxes are too small and the heat transfer coefficients cannot be calculated with accuracy. At these points, we assign $h=0$.

At p1, p2, and p3, the two definitions of heat transfer coefficients agree with each other very well (see Figures 28 and 29). At p4, p5, p6, and p7, however, obvious disagreements occur. At these locations, the separation regions are thick and the free-stream velocities are low. The temperature gradients are weak and temperature changes throughout the boundary layer and the free-stream are slight. Therefore, the boundary layer edge is difficult to determine. Heat transfer coefficients based upon adiabatic wall temperatures are preferred.

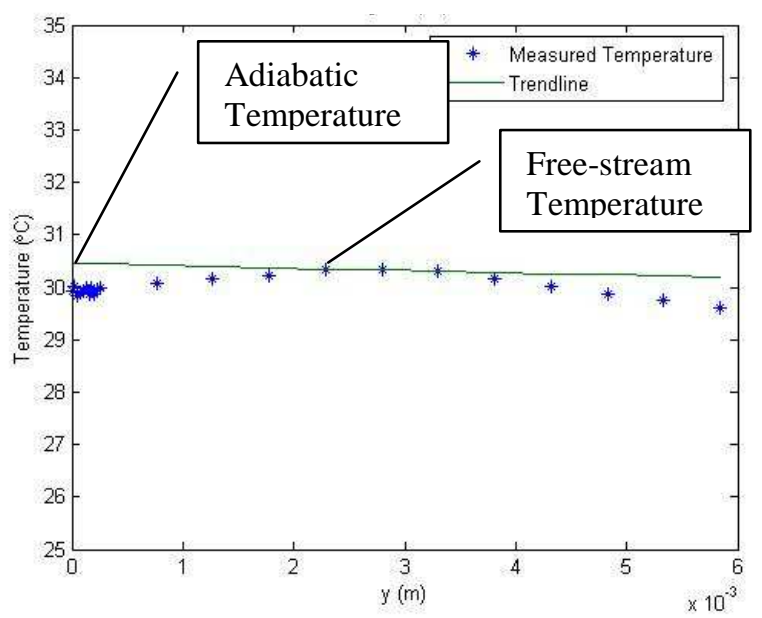

Figure 27 An example for determining the adiabatic wall temperature, $T_{a w}\left(\mathrm{p} 3, \theta=328^{\circ}\right)$

Figure 28 shows the heat transfer coefficients, versus location. The heat transfer coefficients at p2 are larger than those at p1 and p3. That is because, at p2, the flow is turning in direction due to the wall curvature. The heat transfer coefficients at p5, p6, and p7 are of the same level as p2, if the heat transfer coefficients when the velocity is around zero are not considered, e.g. the heat transfer coefficients around $\theta=0^{\circ}$, $180^{\circ}$, and $360^{\circ}$.

Figure 30 shows the ensemble-averaged Stanton numbers, defined as:

$$
S t=\frac{h}{\rho c_{p} V_{\text {displacer }}}
$$

where $\mathrm{V}_{\text {displacer }}=\mathrm{X}_{\text {max }} \omega \cos (\omega \mathrm{t})$. When the $V_{\text {displacer }}=0, S t$ is set to 0 .

The Stanton number distributions, with position on the heater head inner surface and time within the oscillatory cycle, can be applied to a Stirling cycle engine of the geometry of this test, operating at the Valensi and Reynolds numbers of this test. It is not entirely clear how the values might be modified for other geometries and operating conditions. Most of the free-piston engines have a "pressure vessel head" shape for the head geometry, the same as that applied in this study These results could be applied to that family of engines. Based upon experiences with turbulent pipe or boundary layer flows, one might expect that the values, normalized as Stanton numbers, will change with the Reynolds number to the negative $0.20-0.25$ power, as with the turbulent pipe or boundary layer flows. The results will be Valensi number dependent. The Valensi number of this study, scaled with the displacer diameter, is not a proper ratio of diffusion time to cycle period. If converted to one based upon an average flow passage width as the length scale, it might be more suitable for 
physical interpretation. For this test, this Valensi number would be roughly: $\mathrm{Va}_{\text {physical }} \approx 50$. In considering diffusion, it is tempting to use the turbulent viscosity rather than the molecular viscosity. The ratio between the two is variable, but in this flow, a ratio of about $10-20$ is reasonable. With this change, the Valensi number becomes 2.5-5. Since it is above unity, it still indicates sensitivity to frequency.

To use the Stanton number distribution presented in Figure 30 for computing wall heat flux distributions, one must determine the temperature difference driving the heat transfer. An estimate of the average temperature of the fluid within the head region and the known distribution of heater head wall temperature would allow use of the measured Stanton numbers to make an estimate of the time and space-varying heat fluxes. This would be very approximate. This model could be improved upon with a time-resolved, 1-D model, such as Sage (Gedeon, 1999), to evaluate the spatiallyaveraged, but time-resolved expansion space fluid temperatures. A more accurate method for application of these data is to compute the spatially-resolved flow and thermal fields by applying the Stanton numbers of this report and the known wall temperature distribution. This can be done accurately with a rather coarse axisymmetric CFD model. Note that the near-wall region need not be finely resolved for the heat transfer coefficients are given to the analysis and are not computed. When converged, this would give a good estimate of the spatial and time-resolved temperature field and adiabatic wall temperatures. The wall heat flux values could be computed from the Stanton number data.

It is important to note that this Stanton number characterizes the convective heat flux. It does not include the heat flux associated with isentropic compression heating and isentropic expansion cooling of the Stirling cycle fluid. This component of heat flux could be computed separately and superposed on the heat flux by convection computed from the convective Stanton number results presented in this report.

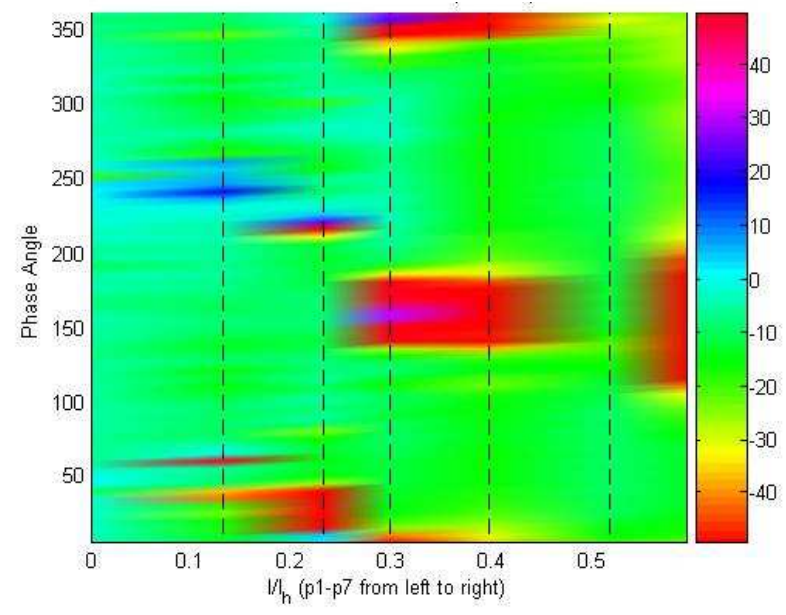

Figure 28 Ensemble-averaged heat transfer coefficients based on adiabatic wall temperature versus location in the cycle

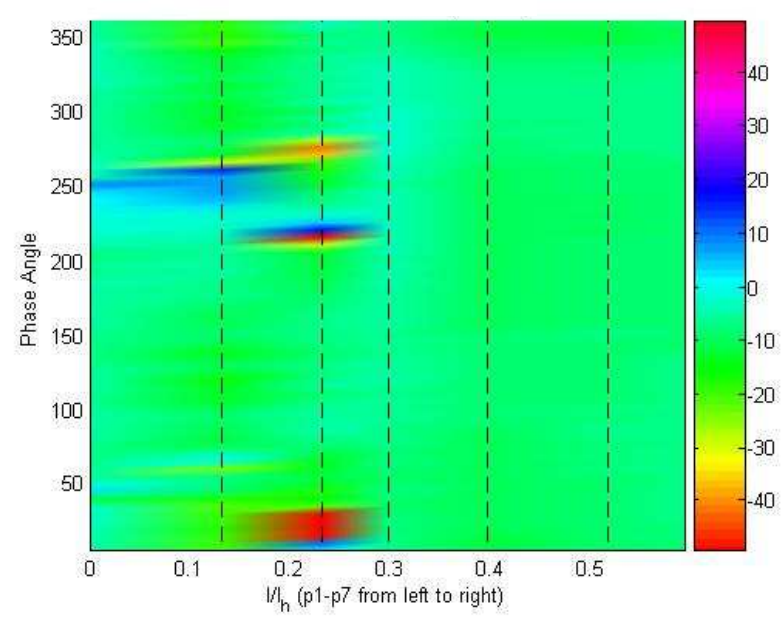

Figure 29 Ensemble-averaged heat transfer coefficients based on temperature at infinity versus the location in the cycle

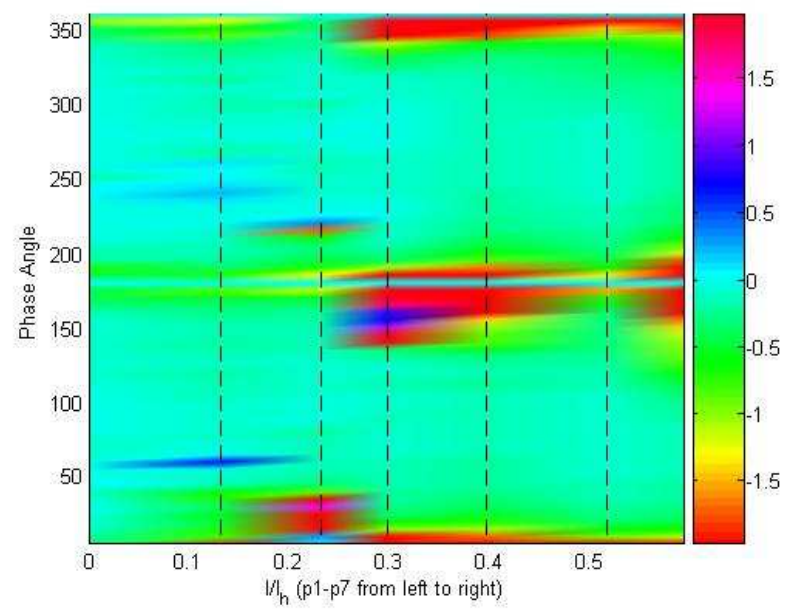

Figure 30 Ensemble-averaged Stanton numbers based on adiabatic wall temperature versus the location in the cycle 


\section{Conclusions}

The velocity and temperature profiles are measured under oscillatory flow conditions simulating flow in the expansion space of a Stirling cycle engine. The unsteady heat fluxes, heat transfer coefficients, and Stanton numbers are obtained from the measurements. The flow separates from the head surface due to the curved wall geometry and the adverse temporal pressure gradients. Flow visualization, velocity measurements, and thermal measurements show very consistent behavior. The average heat transfer coefficients are remarkably low. This is because of the thick boundary layers and separation zones on the head inner wall.

The measured Stanton numbers could be used in conjunction with coarse CFD models to compute heater head wall heat flux distributions. A short discussion on this is presented. The measured velocities and temperatures could be compared with numerical simulations of the test rig to aid in validation of multidimensional design codes.

\section{References}

Adolfson, D. A., Simon, T. W., Ibrahim, M. B., and Gedeon, D., 2002, "Measurements in Oscillatory Flows with Separation in Support of Stirling Engine Model Development," IECEC 2002 Paper No. 20142, 2002 IECEC Conf., Washington D.C.

Adolfson, D. A., Simon, T. W., Ibrahim, M. B., and Gedeon, D., 2003, "Unsteady Fluid Dynamics Simulation of a Stirling Engine Heater Head," Paper \# AIAA-2003-5934, 2003 IECEC Conf., Portsmouth VA.

Adolfson, D. A., Simon, T. W., and Ibrahim, M. B., 2004, "Measurements, Computation and Analysis of a SemiConstrained, Axi-symmetric Jet," ASME GT2004-54215, Presented at the 2004 Int'l. Gas Turbine Conference, Vienna, Austria.

Eckert, E. R. G., 1984, “Analysis of Film Cooling and Full-Coverage Film Cooling of Gas Turbine Blades, ' ASME J. Eng. Gas Turbines Power, Vol. 106, pp. 206-213.

Gilard, V. and Brizzi, L., 2005, "Slot Jet Impinging on a Concave Curved Wall," Journal of Fluids Engineering, May 2005, Vol. 127.

Gedeon, D., 1999, "Sage User Manual," $3^{\text {rd }}$ ed., Gedeon Associates, 16922 South Canaan Road, Athens, OH, 45701, USA. 


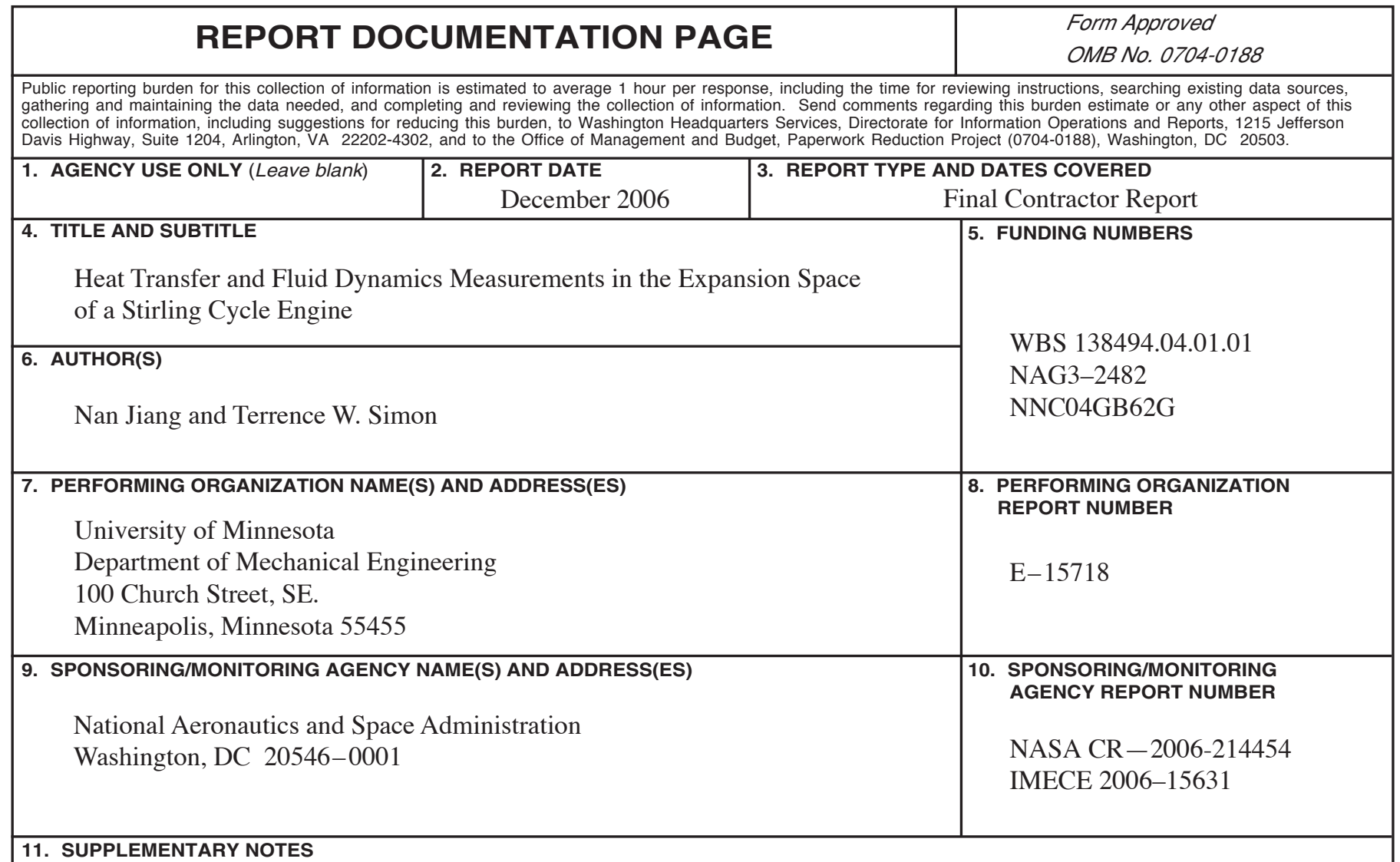

Prepared for the International Mechanical Engineering Congress and Exposition sponsored by the American Society of Mechanical Engineers, Chicago, Illinois, November 5-10, 2006. Project manager, Roy C. Tew, organization code RPT, 216-433-8471.

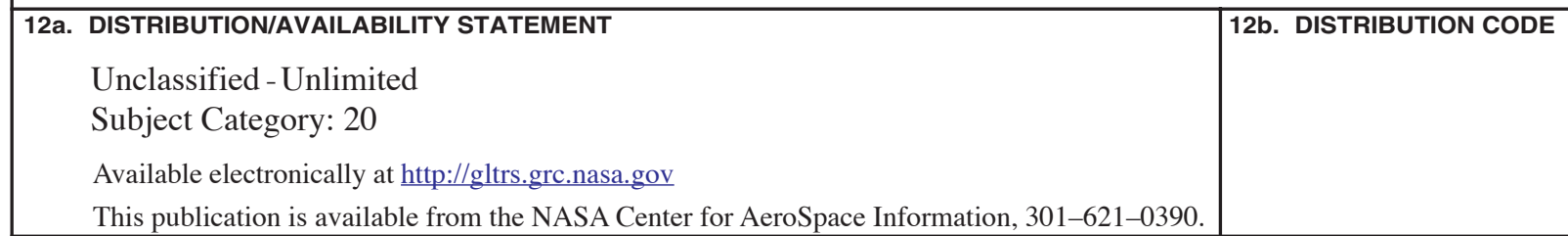

13. ABSTRACT (Maximum 200 words)

The heater (or acceptor) of a Stirling engine, where most of the thermal energy is accepted into the engine by heat transfer, is the hottest part of the engine. Almost as hot is the adjacent expansion space of the engine. In the expansion space, the flow is oscillatory, impinging on a two-dimensional concavely-curved surface. Knowing the heat transfer on the inside surface of the engine head is critical to the engine design for efficiency and reliability. However, the flow in this region is not well understood and support is required to develop the CFD codes needed to design modern Stirling engines of high efficiency and power output. The present project is to experimentally investigate the flow and heat transfer in the heater head region. Flow fields and heat transfer coefficients are measured to characterize the oscillatory flow as well as to supply experimental validation for the CFD Stirling engine design codes. Presented also is a discussion of how these results might be used for heater head and acceptor region design calculations.

14. SUBJECT TERMS

Stirling engines; Stirling coolers/cryocoolers; Regenerators; Heat exchanger

15. NUMBER OF PAGES

18

16. PRICE CODE

17. SECURITY CLASSIFICATION OF REPORT

18. SECURITY CLASSIFICATION OF THIS PAGE

Unclassified

Unclassified

19. SECURITY CLASSIFICATION
OF ABSTRACT

20. LIMITATION OF ABSTRACT

NSN 7540-01-280-5500

Standard Form 298 (Rev. 2-89)

Prescribed by ANSI Std. Z39-18 298-102 

